\title{
Epitope analysis of antibodies recognising the cell proliferation associated nuclear antigen previously defined by the antibody $\mathrm{Ki}-67$ (Ki-67 protein)
}

\author{
M H G Kubbutat, G Key, M Duchrow, C Schlüter, H-D Flad, J Gerdes
}

\begin{abstract}
Aims-To elucidate the fine specificities of the antibodies MIB 1 and MIB 3 and of additional monoclonal antibodies which also recognise the Ki-67 protein (MIB 5, IND.64, JG-67-2a).

Methods-Different parts of the Ki-67 protein cDNA were expressed in Escherichia coli. Bacterial lysates were separated by sodium dodecyl sulphate-polyacrylamide gel electrophoresis (SDS-PAGE) and blotted on to nitrocellulose. Additionally different peptides were synthesised on a membrane support (SPOT-Blot). The immunoreactivity of the antibodies with the recombinant proteins and the immobilised synthetic peptides, respectively, was analysed. A competition enzyme linked immunosorbent assay (ELISA) using a soluble synthetic peptide was also performed.

Results-The epitopes of all antibodies tested were contained within the same region of seven amino acids. The antibodies MIB 1 and MIB 3 required the five amino acid sequence FKELF for binding, whereas Ki-67, JG-67-2a, MIB 5 and IND.64 detected the sequence FKEL.

Conclusions-It is concluded that the amino acid sequence FKELF represents an immunodominant area of the $\mathrm{Ki}-67$ protein and that there is no correlation between the ability to detect the Ki-67 protein in paraffin wax sections irradiated with microwaves and the epitopes recognised by the antibodies.
\end{abstract}

(F Clin Pathol 1994;47:524-528)

The monoclonal antibody $\mathrm{Ki}-67$ was found in 1983 after mouse myeloma cells had been fused with the spleen cells of mice immunised with nuclei of L 428 cell line cells. ${ }^{1}$ Detailed cell cycle analysis showed that this antibody detects a nuclear antigen (Ki-67 protein) which is exclusively expressed in proliferating cells-that is, in $G_{1}, S, G_{2}$ phases, and mitosis, but not in $\mathrm{G}_{0}{ }^{2}$

Because of these properties, $\mathrm{Ki}-67$ has become a powerful tool during the past decade for estimating the growth fraction in malignant disease, based on numerous studies which have consistently shown that there is a highly significant correlation between the mean values of the growth fraction deter- mined with the monoclonal antibody $\mathrm{Ki}-67$ and the histopathological grade of malignancy. ${ }^{3-5}$

The inherent drawback of $\mathrm{Ki}-67$ is that it can be applied only to fresh material, and not routinely formalin fixed and paraffin wax embedded tissue - and, therefore, in retrospective studies of archival material. Recently, we produced new monoclonal antibodies using a recombinant partial structure of the $\mathrm{Ki}-67$ protein as immunogen. These antibodies, designated MIB 1-3, represent true $\mathrm{Ki}-67$ equivalents as determined by histochemistry and immunobiochemistry. ${ }^{6}$

Two of these new antibodies (MIB 1 and MIB 3) as well as the antibody MIB 5 generated subsequently ${ }^{7}$ can detect the $\mathrm{Ki}-67$ protein in routinely formalin fixed, paraffin wax embedded normal and tumour tissues when using an antigen retrieval method based on microwave treatment. ${ }^{89}$ Thus the new $\mathrm{Ki}-67$ equivalent antibodies MIB 1, 3, and 5 now permit the detection of the $\mathrm{Ki}-67$ protein on archival material.

First studies showed that the epitopes of MIB 1, MIB 3, and $\mathrm{Ki}-67^{6}$ as well as that of MIB 5 (unpublished results) are located on an identical stretch of 20 amino acids within the $\mathrm{Ki}-67$ protein. This sequence represents a part of the highly conserved 22 amino acid element called "Ki-67 motif". In the Ki-67 protein it appears 16 times with a homology between $72 \%$ and $100 \%$ with regard to the amino acid sequence (fig $1 \mathrm{~A}) .{ }^{10}$

Because of the importance of estimating the $\mathrm{Ki}-67$ growth fraction, the aim of our study was to elucidate the fine specificities of antibodies directed against the $\mathrm{Ki}-67$ protein within the 22 amino acid sequence mentioned above, and to compare the epitopes recognised by the antibodies MIB 1, 3, 5, Ki-67, and JG-67$2 \mathrm{a}^{11}$ and the recently described monoclonal antibody IND.64, ${ }^{12}$ which represents an additional $\mathrm{Ki}-67$ equivalent antibody. ${ }^{13}$

\section{Methods}

All amino acid sequences mentioned are written in the one letter code from the $\mathrm{N}$-terminus to the C-terminus (from left to right).

Antibodies MIB 1, 2, 3, and 5, Ki-67 and IND.64 were generated as described ${ }^{1612}$; JG$67-2 \mathrm{a}$ is a subclass switch variant of the original $\mathrm{Ki}-67$ antibody. ${ }^{11}$ Gal 1 is a monoclonal anti- $\beta$ galactosidase antibody produced in our laboratory. 


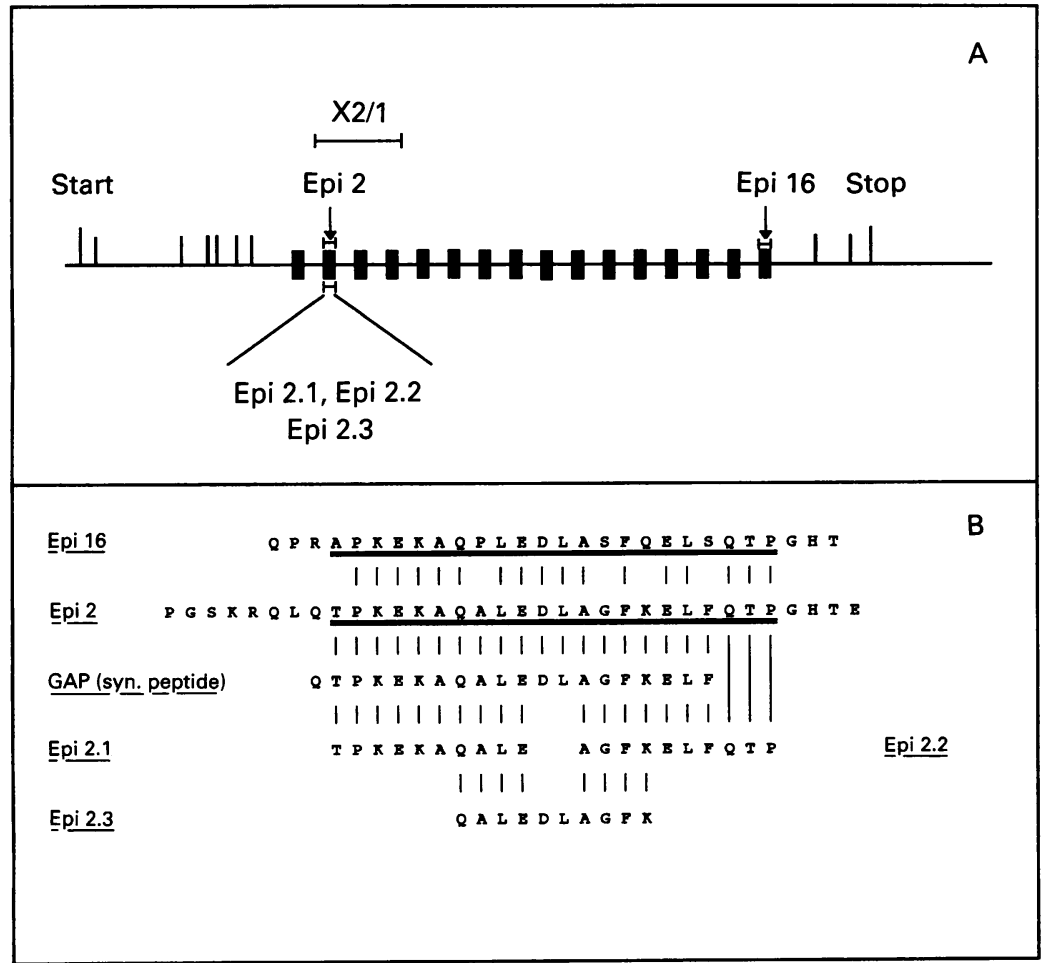

Figure 1 A: Schematic structure of the Ki-67 protein cDNA. The positions of the cloned sequences are indicated. Marked boxes represent the 16 repeats called "Ki-67 motifs" which show a homology between $72 \%$ and $100 \%$ with regard to the corresponding amino acid sequence. B: Amino acid sequences used in this study. Sequence Epi 2, Epi 16, Epi 2.1, Epi 2.2 and Epi 2.3 were expressed as part of fusion proteins in $E$ coli, whereas the peptide GAP was synthesised and used in a competition assay by ELISA. Double underlined sequences represent the "Ki-67 motifs"; single lines mark positions of identical amino acids. columns (Diagen, Hilden, Germany). Sequencing of purified plasmids was performed on an ALF DNA sequencer according to the manufacturer's recommendation (Pharmacia, Freiburg, Germany).

\section{SDS-PAGE AND IMMUNOBLOTTING}

Preparation of bacterial cell lysates for SDSPAGE was performed as described. ${ }^{6}$ Lysates of bacteria were separated on reducing $7.5 \%$ separation gels with $3 \%$ stacking gels. Molecular weight markers were obtained from Sigma (Munich, Germany). Proteins were transferred to nitrocellulose membranes (BA 85, Schleicher \& Schuell, Dassel, Germany) by western blot technique ${ }^{16}$ in a Biometra (Göttingen, Germany) semi-dry blotting apparatus (two hours at $150 \mathrm{~mA}$ ).

Unoccupied protein binding sites of the nitrocellulose were blocked by incubation for one hour with blocking solution ( $2 \%$ bovine serum albumin (BSA), $0.05 \%$ Triton X-100 in TRIS-buffered saline (TBS)). After one hour of incubation with primary antibody and thorough washing with TBS the bound antibody was targeted with goat anti-mouse alkaline phosphatase conjugate (Dianova, Hamburg, Germany), diluted 1 in 10000 in blocking solution.

The phosphatase activity was visualised using nitro blue tetrazolium (NBT) and 5bromo-4-chloro-3-indolyl phosphate (BCIP) as substrate. ${ }^{17}$

\section{SPOT-BLOT}

Nucleic acid sequences encoding for amino acid sequences of Epi 2 and Epi 16 (figs 1A and $B$ ), respectively, derived from the $\mathrm{Ki}-67$ protein CDNA, were amplified from IM-9 cDNA (ATCC No. CCL 159) using the polymerase chain reaction (PCR). The fragments were cloned between the $E c o$ RI and $B g l$ II site of the expression vector pAX $4 a+{ }^{14}$ (Medac, Hamburg, Germany). The resulting plasmids were transformed into $E$ coli DH5aIQ (Gibco BRL, Berlin, Germany).

Sense and antisense strands of the sequences encoding for Epi 2.1, 2.2, and 2.3 (figs 1A and B) were synthesised on a Beckman DNA-SM Synthesizer (Beckman, Munich, Germany) with additional bases on the $5^{\prime}$ and $3^{\prime}$ end to form restriction sites after hybridisation. The corresponding sense and antisense strands were hybridised by heating for 10 minutes to $95^{\circ} \mathrm{C}$ and slowly cooling down to room temperature. The double strand fragments were separated on nondenaturing PAGE and eluted from the gel by the "crush and soak" method. ${ }^{15}$ The purified fragments were cloned between the $B g l$ II and Sal 1 site of the pAX $4 \mathrm{a}+$ vector and transformed into $E$ coli DH5aIQ.

All resulting plasmids carried a gene which encodes for a fusion protein containing bacterial $\beta$-galactosidase and the respective part of the $\mathrm{Ki}-67$ protein.

\section{SEQUENCING OF INSERTS}

Plasmids of successfully transformed $E$ coli clones were isolated using Qiagen Tip-100
Solid phase peptide synthesis on a special membrane support (SPOT-Blot) was performed according to the manufacturer's instructions for the membrane (ICI, Cambridge Research Biochemicals, Norwich, England).

Blocking of unoccupied protein binding sites, incubation, and detection of bound antibodies were performed as described above. Synthesised peptide sequences are shown in fig 5 .

\section{COMPETITION ASSAY BY ELISA}

Competition assay by ELISA was performed as described before. ${ }^{6}$ Briefly, polystyrene microtitre plates were coated with lysates of bacteria expressing a part of the $\mathrm{Ki}-67$ protein cDNA (X2/1) (fig 1A), known to include the epitopes of all antibodies tested. ${ }^{6713}$ Anticoncentrations of the synthetic peptide, designated GAP (fig 1B), for 30 minutes before being subjected to precoated microtitre plates. After incubation for one hour bound antibodies were detected using a goat anti-mouse alkaline phosphatase conjugate in combination with a phosphatase substrate (Sigma, Munich, Germany). Finally, optical density was determined at $405 \mathrm{~nm}$.

Synthetic peptide GAP was synthesised by Dr Kullmann, Institut für Neurobiochemie, Hamburg, Germany.

\section{Results}

All cloned inserts used in this study were fully bodies were incubated with different 
Summary of biochemical and immunohistochemical properties of the Ki-67equivalent antibodies used in this study

\begin{tabular}{|c|c|c|c|c|c|c|c|}
\hline \multirow[b]{2}{*}{ Antibody } & \multirow[b]{2}{*}{ Subclass } & \multirow[b]{2}{*}{ Immunogen } & \multicolumn{2}{|c|}{$\begin{array}{l}\text { Immunohistochemical detection of } \\
\text { the Ki-67 protein on }\end{array}$} & \multicolumn{2}{|l|}{ Western blot } & \multirow[b]{2}{*}{ Reference } \\
\hline & & & $\begin{array}{l}\text { Frozen } \\
\text { sections }\end{array}$ & $\begin{array}{l}\text { Microwave treated } \\
\text { paraffin wax } \\
\text { sections }\end{array}$ & $\begin{array}{l}\text { Native Ki-67 } \\
\text { protein } \\
\text { (IM-9 lysate) }\end{array}$ & $X 2 / 1$ & \\
\hline Ki-67 & $\operatorname{IgG} 1 \kappa$ & \multirow{2}{*}{$\begin{array}{l}\text { Nuclei of L } 428 \\
\text { cell line cells } \\
\varphi \rrbracket\end{array}$} & +9 & - & + & + & 1,6 \\
\hline JG-67-2a & $\operatorname{IgG} 2 \mathrm{a} \kappa$ & & + & - & + & + & $\begin{array}{l}\text { 11, } \\
\text { unpublished } \\
\text { data }\end{array}$ \\
\hline \multirow[t]{2}{*}{$\begin{array}{l}\text { MIB } 1 \\
\text { MIB } 2 \\
\text { MIB 3 } \\
\text { MIB } 5 \\
\text { IND } 64\end{array}$} & \multirow[t]{2}{*}{$\begin{array}{l}\operatorname{IgG} 1 \kappa \\
\operatorname{IgG} 1 \kappa \\
\operatorname{IgG} 1 \kappa \\
\operatorname{IgG} 1 \kappa \\
\operatorname{IgG} 2 \mathrm{~b} \kappa\end{array}$} & $\begin{array}{l}\mathrm{X} 2 / 1 \dagger \\
\mathrm{X} 2 / 1 \\
\mathrm{X} 2 / 1 \\
\mathrm{X} 2 / 1 \\
\text { Spleen cells of nude }\end{array}$ & $\begin{array}{l}+ \\
+ \\
+ \\
+\end{array}$ & $\begin{array}{l}+ \\
- \\
+ \\
+\end{array}$ & $\begin{array}{l}+ \\
+ \\
+ \\
+\end{array}$ & $\begin{array}{l}+ \\
+ \\
+ \\
+\end{array}$ & $\begin{array}{l}6 \\
6 \\
6 \\
7\end{array}$ \\
\hline & & $\begin{array}{l}\text { mice grafted with } \\
\text { Ichikawa tumor }\end{array}$ & + & - & + & + & 12,13 \\
\hline
\end{tabular}

JUG-67-2a is a subclass switch variant of the original $\mathrm{Ki}-67 ; \nmid \mathrm{X} 2 / 1$ is a recombinant fusion protein containing $\beta$-galactosidase and a part of the $\mathrm{Ki}-67$ protein; It reacts with; - no reaction.

sequenced and controlled with regard to the reading frame and the sequence.

COMPARISON OF IMMUNOHISTOCHEMICAL AND BIOCHEMICAL CHARACTERISTICS OF

ANTIBODIES INVESTIGATED

The table summarises the immunohistochemical and biochemical data of the $\mathrm{Ki}-67$ equivalent antibodies used in this study. All antibodies except JG-67-2a (IgG $2 a \kappa$ ) and IND.64 (IgG $2 \mathrm{~b} \kappa$ ) are of the IgG $1 \kappa$ subclass. The immunogen of MIB $1,2,3$ and 5 was a recombinant fusion protein including a part of the $\mathrm{Ki}-67$ protein, designated $\mathrm{X} 2 / 1$. It contains three of the 16 repeats ("Ki-67 motifs") occurring in the $\mathrm{Ki}-67$ protein (fig $1 \mathrm{~A}$ ) and was applied for immunisation after complete denaturation of the protein. The immunogen for the generation of the original monoclonal antibody $\mathrm{Ki}-67$ consisted of isolated nuclei of L428 cell line cells; IND.64 was produced using spleen cells of nude mice grafted with Ichikawa tumour as immunogen. On frozen sections of proliferating tissues, such as human tonsils, all antibodies show an identical staining pattern. On the other hand, only MIB 1, 3, and 5 can stain proliferating cells in formalin fixed, paraffin wax embedded tissue sections after microwave treatment. In western blots all antibodies stain the $\mathrm{Ki}-67$ protein in IM-9 cell lysates as well as the recombinant part of the $\mathrm{Ki}-67$ protein $(\mathrm{X} 2 / 1)$.

IMMUNOREACTIVITY OF ANTIBODIES WITH BACTERIALLY EXPRESSED PROTEINS DEDUCED FROM THE KI-67 PROTEIN CDNA

Monoclonal antibody MIB 2 detects an epitope which is localised within the sequence $\mathrm{X} 2 / 1$ except that part which is named Epi 2 (fig 1A). ${ }^{6}$ Its epitope is not further characterised. The monoclonal antibody MIB 2 served as negative control in all experiments performed during this study, as we concentrated our analysis on sequence Epi 2. Accordingly, the monoclonal antibody Gal 1 recognising the $\beta$-galactosidase protein was used as positive control for the expression of fusion protein. Thus negative results obtained with MIB 2 and positive results of Gal 1 on western blots of bacterial lysates, respectively, are not mentioned further.
Figure 2 summarises the results obtained with the different $\mathrm{Ki}-67$ equivalent antibodies applied on western blots of bacterial lysates after expressing the "Ki-67 motif" sequences Epi 2 and Epi 16, respectively. All antibodies detect the fusion protein containing the sequence Epi 2, whereas no antibody binds to the Epi 16 sequence.

\section{COMPETITION ASSAY BY ELISA}

The binding of all $\mathrm{Ki}-67$ equivalent antibodies to the recombinant fusion protein $\beta$-galactosidase/X2/1 was inhibited by the synthetic peptide GAP (fig 3). This result is well in line with those obtained with the recombinant fusion protein ( $\beta$-galactosidase/Epi 2) as described above (fig 2 ).

\section{IMMUNOREACTIVITY OF ANTIBODIES WITH BACTERIALLY EXPRESSED PEPTIDES DEDUCED FROM KI-67 PROTEIN CDNA}

To elucidate further the epitopes of the antibodies within the Epi 2 sequence, we constructed three plasmids which encode for three different fusion proteins. The fusion proteins consist of $\beta$-galactosidase and one of three different but overlapping 10 amino acid sequences (Epi 2.1, 2.2, and 2.3), each representing a partial sequence of Epi 2 (fig 1B). As shown in fig 4, all antibodies exclusively recognise the fusion protein containing the Epi 2.2 sequence, but not those including the Epi 2.1 or Epi 2.3 sequence. The results shown in figs 2,3 , and 4 show that all antibodies react with the Epi 2 and GAP sequence as well as with the Epi 2.2 sequence, but not with Epi 16, Epi 2.1, and Epi 2.3. Thus we assumed the seven amino acid sequence AGFKELF to be the region in which the epitopes of the antibodies are located, as this sequence appears in all constructions which lead to a positive reaction of the antibodies.

SPOT-BLOT

To localise the epitope within the sequence AGFKELF we synthesised six different overlapping heptapeptides (fig 5A) on a membrane support. With these different peptides we covered the amino acid sequence DLAGFKELFQTP. Because we could 


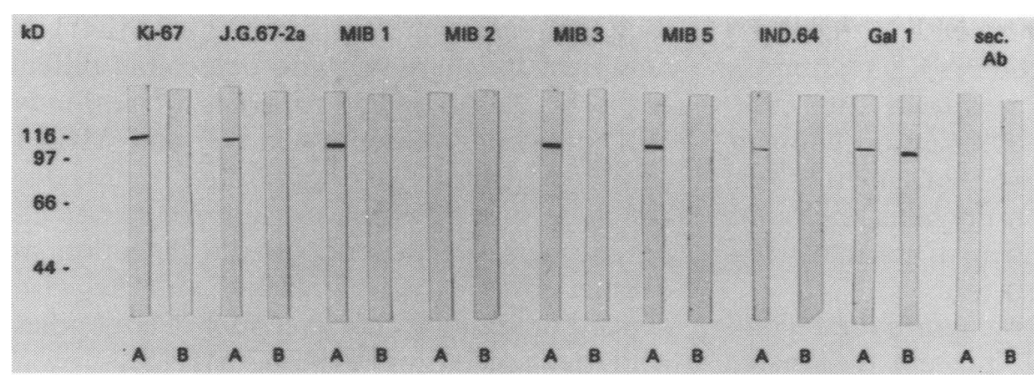

Figure 2 Immunoblot analysis of recombinant parts of the Ki-67 protein with different Ki-67 equivalent antibodies. Lane A: bacteria lysates after expression of $\beta$ galactosidase/Epi 2 fusion protein; lane B: as lane A, but with sequence Epi 16.

exclude that the antibody MIB 2 recognises any sequence used in the SPOT-blot (see above), only those signals were regarded as positive which showed a stronger intensity than those obtained with the antibody MIB 2 .

Figure $5 \mathrm{~B}$ shows that the antibodies $\mathrm{Ki}-67$, JG-67-2a, MIB 5, and IND.64 detect only those peptides that include the four amino

Figure 3 Results of competition assay by ELISA using synthetic peptide GAP. ( $: K i-67$ $+: \mp G-67-2 a, X: M I B 1$, : $M I B$ 2,X. $M I B 3, \bullet$ : MIB 5, $\triangle$ : IND. 64) The binding of all antibodies except MIB 2 to the solid phase-bound fusion protein $\beta$-galactosidase/X2/1 was inhibited by the synthetic 20 amino acid peptide designated $G A P$.
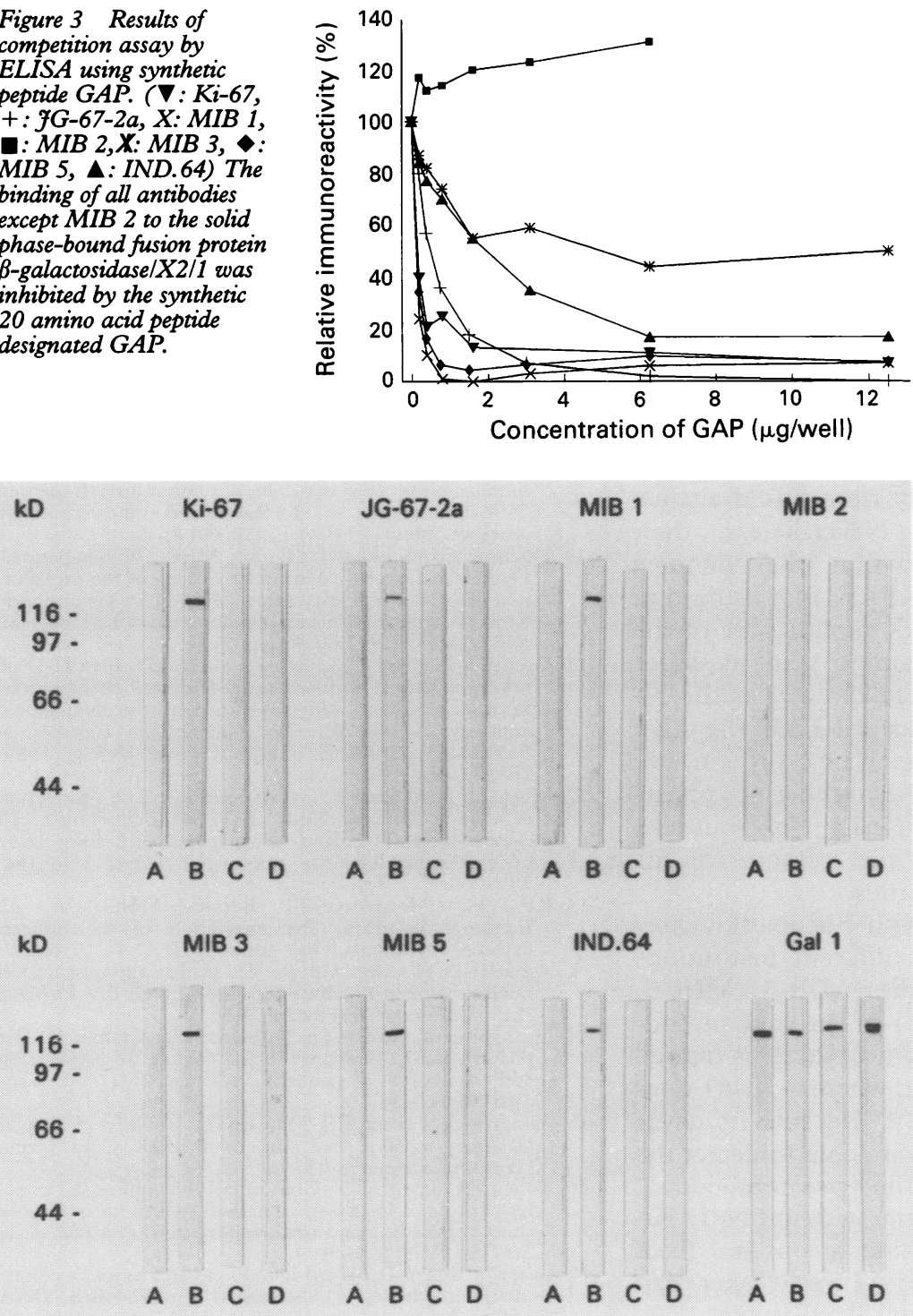

Figure 4 Immunoblot analysis of recombinant peptides with different Ki-67 equivalent antibodies. Lane A: bacteria lysates after expression of $\beta$-galactosidase/Epi 2.1 fusion protein; lane B: as lane $A$, but with sequence Epi 2.2, lane $C$ : as lane $A$, but with sequence Epi 2.3, lane D: as lane $A$, but without any part of the Ki-67 protein sequence.

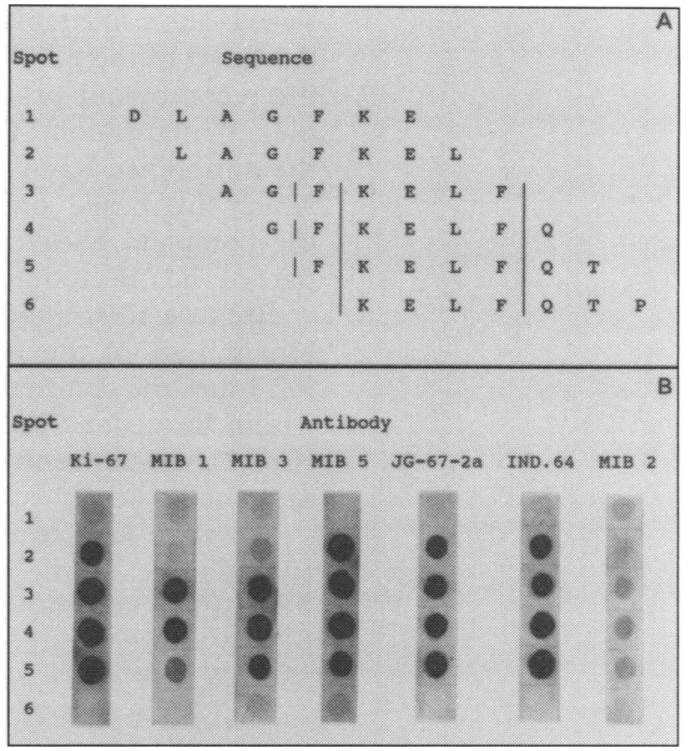

Figure 5 A: Sequences of the six different overlapping heptapeptides used in SPOT-Blot analysis as synthesised on a membrane support. Lines indicate consensus sequence of peptides recognised by monoclonal antibody $K i-67, M I B$ 5, FG-67-2 $a$ and IND. 64; dashed lines indicate consensus sequence of peptides recognised by monoclonal antibody MIB 1 and MIB 3; B: Analysis of different overlapping heptapeptides derived from the Ki-67 protein $c D N A$ for binding of different Ki-67 equivalent antibodies (SPOTBlot analysis). Monoclonal antibodies Ki-67, ҰG-67-2a, $M I B 5$ and IND. 64 detect only peptides including the four amino acid sequence FKEL; MIB 1 and MIB 3 detect only those including the amino acid sequence FKELF. MIB 2 was used as negative control. Solid lines mark consensus sequence for $K i-67, \mathcal{F} G-67-2 a, M I B 5$ and IND. 64; dashed lines enclose consensus sequence for $M I B$ 1 and $M I B 3$

acids sequence FKEL (spot Numbers 2, 3, 4 and 5), whereas the antibodies MIB 1 and MIB 3 react only with those containing the sequence FKELF (spot numbers 3, 4 and 5).

\section{Discussion}

For nearly one decade the monoclonal antibody $\mathrm{Ki}-67$ remained a unique reagent. Due to the fact that we succeeded in sequencing the cDNA of the Ki-67 protein, ${ }^{7}$ a set of antibodies was raised against a recombinant part of the Ki-67 protein (MIB 1, 2, 3, and 5). ${ }^{6}$ Another Ki-67 equivalent antibody (IND.64) was found by using splenocytes of mice grafted with Ichikawa tumour for somatic cell fusion. Some of the new antibodies might gain the same importance for immunohistopathological purposes as the original $\mathrm{Ki}-67$ antibody, because they overcome the drawback that the application of $\mathrm{Ki}-67$ is limited to fresh material (MIB 1, 3, and 5) and may permit double immunostaining due to different antibody subclasses (IND.64), respectively. Hence, the aim of our study was to elucidate the fine specificities of antibodies that recognise the cell proliferation associated nuclear antigen previously defined by the monoclonal antibody $\mathrm{Ki}-67$.

The antibodies investigated can be divided into two groups with regard to the immunogens used for their generation. The first group includes antibodies (MIB 1, 2, 3, and 5) 
raised after immunisations with a recombinant part of the Ki-67 protein (X2/1); notably the recombinant protein was used after complete denaturation. The other group contains the antibodies Ki-67, JG-67-2a, and IND.64 which are based on immunogens including the complete $\mathrm{Ki}-67$ antigen in its native (as part of the injected nuclei) form.

Because all antibodies recognise the recombinant part of the $\mathrm{Ki}-67$ protein designated $\mathrm{X} 2 / 1$ and the fact that some detect a sequence within the second repeat of the $\mathrm{Ki}-67$ protein (Epi 2), we concentrated our analysis on this sequence.

We were able to elucidate the epitopes of all antibodies to the five amino acid sequence FKELF. In contrast to antibodies MIB 1 and MIB 3, which required all five amino acids for binding, the other antibodies (Ki-67, JG-672a, MIB 5 and IND.64) also react with the four amino acid sequence FKEL. Hence all Ki-67 equivalent antibodies show remarkable conformity with regard to their epitopes, obviously regardless of the immunogen used for their generation. The amino acid sequence FKELF occurs in nine of 16 repeats (each with a length of 22 amino acids) of the $\mathrm{Ki}-67$ protein. These repeats show homologies between $72 \%$ and $100 \%$ concerning their amino acid sequence. Comparing the results obtained with the Epi 2 and the Epi 16 sequence (two of these repeats), it becomes clear why no antibody reacts with Epi 16, although these two "Ki-67 motifs" have an overall homology of $77 \%$. The sequence AGFKELF of Epi 2 corresponds to an area in Epi 16, where only four homologous amino acids appear (A-F-EL-), which are also separated by non-homologous amino acids (fig 1B).

The different $\mathrm{Ki}-67$ equivalent antibodies investigated in this study were raised against different immunogens. Nevertheless, their epitopes are located within the identical amino acid sequence FKELF, indicating that this area is an immunodominant part of the $\mathrm{Ki}-67$ protein. As the amino acid sequence EDLAG, which is located directly at the Nterminus of the sequence FKELF (fig 1B), appears 11 times in the $\mathrm{Ki}-67$ protein, we conclude that not only the number of appearances of the sequence FKELF (9x), but also its structure may be the reason for its immunodominant properties.

In previous studies with histopathological material obtained from different institutions we showed that antibodies MIB 1, MIB 3, and MIB 5 stain the $\mathrm{Ki}-67$ protein in routinely processed, paraffin wax sections treated by microwave irradiation, whereas $\mathrm{Ki}-67$ does not (unpublished data). ${ }^{69}$ Recently, Cuavas et al reported that they were able to detect the $\mathrm{Ki}-67$ protein in paraffin wax embedded, microwave treated material with antibody $\mathrm{Ki}$ $67 .{ }^{18}$ However, the staining of optimal fixed tissues by the antibody $\mathrm{Ki}-67$ was weaker than that of MIB 1 in less well fixed tissues. ${ }^{18}$ As there were no differences in staining technique or microwave treatment, we assumed that binding of $\mathrm{Ki}-67$ to its epitope seems to be sensitive to variations in fixation or embed- ding protocols whereas binding of MIB 1 is not. Because there were no detectable differences in the staining properties of antibody MIB 5 (same epitope as $\mathrm{Ki}-67$ ) and MIB 1 (different epitope) (unpublished data), we conclude that different staining properties do not neccessarily depend on the detection of distinct epitopes (Ki-67/MIB 1), but may also depend on binding characteristics of antibodies with identical epitopes (Ki-67/MIB 5).

We thank Claudia Wohlenberg, Bettina Baron, and Rebecca Daßler for their skilful technical assistance.

We thank Professor G Delsol, Groupe d' Étude des Lymphomes Malins et Laboratoire d'Anatomie Pathologique, CHU Purpan, Toulouse, France, for generous supply of antibody IND.64.

The study was supported in part by the Dr Mildred Scheel Stiftung (project W49/90/Ge2).

This work is part of the thesis of MHGK

1 Gerdes J, Schwab U, Lemke H, Stein H. Production of a mouse monoclonal antibody reactive with a human nuclear antigen associated with cell proliferation. Int $\mathcal{f}$ Cancer 1983;31:13-20.

2 Gerdes J, Lemke H, Baisch H, Wacher H-H, Schwab U, Stein $\mathrm{H}$. Cell cycle analysis of a cell proliferationassociated human nuclear antigen defined by the monoassociated human nuclear antigen defined by the mo
clonal antibody Ki-67. F Immunol 1984;133:1710-5.

3 Brown DC, Gatter KC. Monoclonal antibody Ki-67: its use in histopathology. Histopathology 1990;17:489-503.

4 Gerdes J. Ki-67 and other proliferation markers useful for immunohistological diagnostic and prognostic evaluations in human malignancies. In: Osborn $M$, ed. Seminars in Cancer Biology. Vol 1. London: Saunders Scientific Publications, 1990:199-206.

5 Hall PA, Woods AL. Immunohistochemical markers of cellular proliferation: achievements, problems and cellular proliferation: achievements, pro

prospects. Cell Tissue Kinet 1990;23:505-22.
6 Key G, Becker MHG, Baron B, et al. New Ki-67 equivalent murine monoclonal antibodies (MIB 1-3) generated lent murine monoclonal antibodies (MIB 1-3) generated
against bacterially expressed parts of the $\mathrm{Ki}-67 \mathrm{cDNA}$ containing three $66 \mathrm{bp}$ repetitive elements encoding for the Ki-67 epitope. Lab Invest 1993;68:629-36.

7 Schlüter $C$, Duchrow $M$, Wohlenberg $C$, et al. The cell proliferation-associated antigen of antibody $\mathrm{Ki}-67$ : A very large, ubiquitous nuclear protein with numerous repeated elements, representing a new kind of cell cyclemaintaining proteins. F Cell Biol 1993;123:513-22.

8 Cattoretti G, Becker MHG, Key G, et al. Monoclonal antibodies against recombinant parts of the $\mathrm{Ki}-67$ antigen (MIB 1 and MIB 3) detect proliferating cells in microwave-processed formalin-fixed paraffin sections. microwave-processed form

9 Gerdes J, Becker MHG, Key G, Cattoretti G. Immunohistological detection of tumour growth fraction (Ki-67 antigen) in formalin-fixed and routinely processed tissues. $\mathcal{F}$ Pathol 1992;168:85-6.

10 Duchrow M, Schlüter C, Becker MHG, Wohlenberg C, Flad H-D, Gerdes J. Molecular cloning of the proliferation associated nuclear antigen defined by the antibody $\mathrm{Ki}-67$ : A unique gene encoding for a new PEST protein. Eur $\mathcal{F}$ Cell Biol 1993;60(Suppl 37):88.

11 Gerdes J, Gerlach C, Stahmer I, Valerio D, Flad H-D. A new monoclonal antibody against the cell proliferationassociated nuclear antigen defined by the monoclonal associated nuclear antigen defined by the monoclonal
antibody Ki-67. In: 7th International Congress of
Immunology: Stuttgart: Gustav Fischer Verlag, 1989: 768 .

12 Meggetto F, Al Saati T, Cohen-Knafo E, et al. Production of a monoclonal antibody (IND.64) identifying a cell cycle-associated antigen using spleen cells from nude mice bearing Ichikawa tumour. $\mathcal{f}$ Pathol 1992;168: 187-96.

$13 \mathrm{Key}$ G, Meggetto F, Becker MHG, et al. Immunobiochemical characterization of the antigen detected by monoclonal antibody IND.64. Evidence that IND.64 reacts with the cell proliferation associated nuclear antigen previously defined by Ki-67. Virchows Arch (Cell Pathol) 1992;62:259-62.

14 Markmeyer P, Rühlmann A, Englisch U, Cramer F. The pAX plasmids: new gene-fusion vectors for sequencing and expression of proteins in Escherichia coli. Gene 1990;93:129-34.

15 Sambrook J, Fritsch EF, Maniatis T. Molecular cloning. A laboratory manual (2nd edn). New York: Cold Spring

Harbour Laboratory, 1989.
16 Towbin H, Staehelin T, Gordon J. Electrophoretical transfer of proteins from polyacrylamide gels to nitrocellulose sheets: procedure and some applications. Proc Natl Acad Sci USA 1979;76:4350-4

17 Leary JJ, Brigati DJ, Ward DC. Rapid and sensitive colorimetric method for visualizing biotin-labeled DNA probes hybridized to DNA or RNA immobilized on nitrocellulose: Bio-blots. Proc Natl Acad Sci USA 1983;80:4045-9.

18 Cuevas E, Jones DB, Wright DH. Immunohistochemical detection of tumour growth fraction ( $\mathrm{Ki}-67$ antigen) in formalin-fixed and routinely processed tissues. I Pathol 1993;169:477-8. 